\title{
Effects of Three Acepromazine Doses on the Incidence of Morphine-Induced Vomiting, Sedation and Some Physiological Variables in Dogs
}

\author{
Eduardo Raposo Monteiro, ${ }^{1,2}$, Juliana Barros Pinto', \\ Juarez Simões Nunes Junior' ${ }^{2}$ Julia da Penha Piccoli Rangel ${ }^{1}$
}

\begin{abstract}
Background: Acepromazine was found to reduce the incidence of vomiting induced by opioids such as morphine, hydromorphone and oxymorphone in dogs. Despite the effectiveness of the phenothiazine in preventing opioid-induced vomiting in this species, a single dose of acepromazine $(0.05 \mathrm{mg} / \mathrm{kg})$ was tested and the influence of dose on the antiemetic effect of the drug is unknown. The primary objective of this study was to evaluate the effect of three acepromazine doses on the incidence of vomiting induced by morphine in dogs. A secondary aim was to assess the degree of sedation and effects on physiological variables following administration of the combinations tested.

Materials, Methods \& Results: All dogs received $0.5 \mathrm{mg} / \mathrm{kg}$ morphine (IM). Fifteen min before morphine, dogs in the Control, $\mathrm{ACP}_{\mathrm{LD}}, \mathrm{ACP}_{\mathrm{MD}}$ and $\mathrm{ACP}_{\mathrm{HD}}$ groups were administered (IM) physiological saline or acepromazine at doses of 0.025 , 0.05 and $0.1 \mathrm{mg} / \mathrm{kg}$, respectively. In Phase 1, purpose-bred $\operatorname{dogs}(\mathrm{n}=8)$ underwent each of the four treatments in a randomized, crossover design; the incidence of vomiting, sedation, pulse rate (PR), systolic, mean and diastolic blood pressures (SAP, MAP and DAP) were investigated for $60 \mathrm{~min}$. Sedation was assessed by a numeric descriptive scale (NDS, range 0-3) and a simple numerical scale (SNS, range 1-10). In Phase 2, client-owned dogs $(\mathrm{n}=50)$ received a single treatment and only the incidence of vomiting was assessed. There was no significant difference between groups on the incidence of vomiting recorded in Phase 1, Phase 2 and the average of Phases 1 and 2. A significant decrease in PR was observed in most groups but no significant difference was detected between groups. Blood pressure decreased in all groups; during most of the evaluation period, SAP, MAP and DAP were significantly higher in the Control than in other treatments. Dogs in this study presented mild to intense sedation. A significant difference in NDS scores was observed between the Control and $\mathrm{ACP}_{\mathrm{MD}}$ groups whereas for SNS scores, significant differences were detected between the $\mathrm{ACP}_{\mathrm{MD}}$ and $\mathrm{ACP}_{\mathrm{HD}}$ groups compared with the Control group. The number of dogs presenting intense sedation as judged by the NDS (NDS score = 3) were: $1 / 8,3 / 8,3 / 8$ and $4 / 8$ dogs in the Control, $\mathrm{ACP}_{\mathrm{LD}}, \mathrm{ACP}_{\mathrm{MD}}$ and $\mathrm{ACP}_{\mathrm{HD}}$ groups, respectively.

Discussion: The hypothesis of the study was rejected. The acepromazine dose did not influence the frequency of morphineinduced vomiting, the degree of sedation or cardiovascular variables after administration of either treatment. The frequency of vomiting was high $(\geq 75 \%)$ in dogs of the present study regardless of the treatment administered. There was no significant difference in the frequency of vomiting in $\mathrm{ACP}_{\mathrm{LD}}, \mathrm{ACP}_{\mathrm{MD}}$ and $\mathrm{ACP}_{\mathrm{HD}}$ as compared to the Control group. This finding was unexpected because it has been reported in a previous study that acepromazine reduced the incidence of opioid-induced vomiting in dogs. $\mathrm{ACP}_{\mathrm{LD}}, \mathrm{ACP}_{\mathrm{MD}}$ and $\mathrm{ACP}_{\mathrm{HD}}$ improved the quality of sedation compared to the Control treatment but no significant difference in sedation scores was observed among these groups. These findings suggest that, when combined to morphine, there is no improvement in sedation when the acepromazine dose is increased above $0.025 \mathrm{mg} / \mathrm{kg}$ in dogs. Despite a significant decrease, mean values of PR, SAP, MAP and DAP remained within the physiological range for conscious dogs. In summary, none of the acepromazine doses was effective in preventing morphine-induced vomiting in dogs. Sedation is greater after acepromazine-morphine combinations than after morphine alone and is not influenced by the acepromazine dose. Cardiovascular effects induced by combinations administered in this study were well tolerated and of little clinical relevance to healthy conscious dogs.
\end{abstract}

Keywords: emesis, phenothiazine, neuroleptanalgesia, opioid, tranquilizer. 


\section{INTRODUCTION}

Opioid analgesics are the most commonly used drugs to provide intraoperative antinociception in dogs. These drugs can be combined with sedatives, such as acepromazine, to induce sedation and analgesia and such combinations have been named neuroleptanalgesia [12].

In dogs, acepromazine has been used in combination with many opioids such as morphine [2,9,10], methadone [1,7,10], butorphanol [10], fentanyl, pethidine [2], hydromorphone, oxymorphone [14] and tramadol $[8,10]$.

In addition to the sedative effect, acepromazine was also found to possess antiemetic properties. This feature may be of particular interest because acepromazine reduced the incidence of opioid-induced vomiting in dogs [14]. In one study, vomiting was observed in $25 \%$ of dogs administered acepromazine 15 min before morphine, whereas $75 \%$ of dogs vomited when no acepromazine was given before morphine [14]. The effectiveness of acepromazine in reducing the incidence of vomiting in dogs was also reported with the use of hydromorphone and oxymorphone [14]. Despite the effectiveness of the phenothiazine in preventing opioid-induced vomiting in dogs, a single dose of acepromazine $(0.05 \mathrm{mg} / \mathrm{kg})$ was tested and the influence of dose on the antiemetic effect of the drug is unknown.

The primary objective of this study was to evaluate the effect of three acepromazine doses on the incidence of vomiting induced by morphine in dogs. A secondary aim was to assess the degree of sedation and effects on physiological variables following administration of the combinations tested. The hypothesis was that the effects of acepromazine would be dose related.

\section{MATERIALS AND METHODS}

\section{Study design}

This was a 2-phase study. In Phase 1, the effects of acepromazine on the incidence of morphine-induce vomiting, sedation and physiological variables were investigated in purpose-bred dogs $(n=8)$. Each dog underwent four treatments in a randomized, crossover design.

In Phase 2, client-owned dogs $(n=50)$ received a single treatment and only the incidence of morphine-induced vomiting was assessed. Brachycephalic dog breeds were excluded from the study.

\section{Drug treatments}

Each treatment consisted of two intramuscular injections in pelvic limbs. The first injection for the control treatment was $0.025 \mathrm{~mL} / \mathrm{kg}$ of physiological saline. For the $\mathrm{ACP}_{\mathrm{LD}}, \mathrm{ACP}_{\mathrm{MD}}$ and $\mathrm{ACP}_{\mathrm{HD}}$ treatments, the first injection consisted of acepromazine $\left(\text { Acepran }^{\circledR}\right)^{1}$ at doses of $0.025,0.05$ and $0.1 \mathrm{mg} / \mathrm{kg}$, respectively. For all treatment groups, $0.5 \mathrm{mg} / \mathrm{kg}$ morphine $\left(\text { Dimorf }^{\circledR}\right)^{2}$ was administered for the second injection. On all occasions, 15 min were allowed between the first and second injections.

\section{Phase 1}

Eight adult, mongrel, purpose-bred dogs (7 females and 1 male) were used in Phase 1 . Weight of the dogs was $14.9 \pm 3.6 \mathrm{~kg}$ (mean $\pm \mathrm{SD}$ ). Dogs were judged to be healthy based on physical examination and laboratorial findings (CBC and serum chemistry). Food but not water was withheld for $12 \mathrm{~h}$ prior to experiments. Each of 8 dogs was administered the control, $\mathrm{ACP}_{\mathrm{LD}}, \mathrm{ACP}_{\mathrm{MD}}$ and $\mathrm{ACP}_{\mathrm{HD}}$ treatments, on different occasions, in a randomized crossover design with 1-week washout intervals.

Variables recorded included pulse rate (PR), systolic, mean and diastolic blood pressures (SAP, MAP and DAP), degree of sedation, and frequency of vomiting. An oscillometric device (petMAP $\left.{ }^{\circledR}\right)^{3}$ was used to assess PR, SAP, MAP and DAP. The cuff bladder was chosen according to the manufacturer recommendations and was positioned above the carpus. Five consecutive readings were obtained on each time point and the average was taken for analysis. Sedation was assessed by use of a numeric descriptive scale (NDS) and a simple numerical scale (SNS). The NDS ranged from 0 to 3 , as follows: 0 , no sedation; 1 , mild sedation, less alert but still active; 2 , moderate sedation, drowsy, recumbent but can walk; 3 , intense sedation, very drowsy, unable to walk $[9,14]$. The SNS consisted of a scale ranging from 0 to 10 where 0 represents no sedation and 10 represents the most sedation possible [2]. For both the NDS and SNS, only whole numbers could be assigned. Two observers, unaware of the assigned treatment, were responsible for scoring sedation. On each occasion, the scores were recorded after consensus between the observers. Sedation scores, PR, SAP, MAP and DAP were recorded before administration of any drug (baseline), $15 \mathrm{~min}$ after the first injection (time point 15), and 15, 30 and 45 min after the second injection (time points 30, 45 and $60 \mathrm{~min}$ ). 
After administration of morphine (second injection), the dogs were observed during 15 min for the occurrence of vomiting. Vomiting was defined as vigorous abdominal contractions followed by attempts to expel gastric contents, even if nothing has yet been expelled. The time elapsed until vomiting was recorded.

Phase 2

Thirty two client-owned dogs scheduled for diagnostic or surgical procedures needing sedation or general anesthesia were enrolled in Phase 2. All owners gave their informed consent. Dogs were classified as ASA physical status I or II. These 32 dogs were randomly assigned to receive a single treatment (control, $\mathrm{ACP}_{\mathrm{LD}}, \mathrm{ACP}_{\mathrm{MD}}$ or $\mathrm{ACP}_{\mathrm{HD}}$ ). After administration of the experimental treatment, occurrence of vomiting within $15 \mathrm{~min}$ after the second injection (morphine) was registered. Other variables evaluated in Phase 1 experiments were not recorded in Phase 2.

Anesthetic records for other 18 female dogs that had participated in another research study were also included in Phase 2. All of the 18 dogs were administered $0.5 \mathrm{mg} / \mathrm{kg}$ morphine intramuscularly as premedication before an ovariohysterectomy and had the occurrence of vomiting recorded in anesthetic records. Data from these 18 dogs were included in the control group.

\section{Statistical analysis}

Data distribution was checked by the Shapiro-Wilk test. Differences among groups in the frequency of vomiting were compared by a Chi-square test. Weight and age of dogs, and time until first vomiting episode were compared by a Kruskal-Wallis and a Dunn's multiple comparison test. In Phase 1, comparisons of sedation scores among groups were performed with a Friedman test and a Dunn's multiple comparison test. The same approach was used to compare sedation scores after administration of injections with baseline values. For parametric data (PR, SAP, MAP and DAP), differences among groups were analyzed with a two-way repeated measures analysis of variance (ANOVA) and a Bonferroni correction for multiple pairwise comparisons. For comparisons over time within a group (versus baseline values), a one way repeated measures ANOVA and a Dunnett post hoc test were performed. For all analyses, a $P$ value of $<0.05$ was considered significant.

\section{RESULTS}

Phase 1

The frequency of vomiting and time until first vomiting episode are summarized in Table 1. There were no significant differences between groups.

A significant decrease in PR was observed in the control and $\mathrm{ACP}_{\mathrm{HD}}$ groups at selected time points. In the $\mathrm{ACP}_{\mathrm{LD}}$ and $\mathrm{ACP}_{\mathrm{MD}}$ groups, $\mathrm{PR}$ decreased numerically but not significantly. There was no significant difference between groups in PR throughout the experiments (Table 2). In the control group, MAP and DAP decreased bellow baseline values from 15 to 45 min whereas SAP did not change significantly over time. In the $\mathrm{ACP}_{\mathrm{LD}}, \mathrm{ACP}_{\mathrm{MD}}$ and $\mathrm{ACP}_{\mathrm{HD}}$ groups, $\mathrm{SAP}$, MAP and DAP were lower than baseline values from 15 to 60 min. During most of the evaluation period, SAP, MAP and DAP were significantly higher in the control than in other treatments (Table 2).

One dog in the control treatment did not develop evidence of sedation (NDS score $=0$ ). All other dogs in the control and remaining treatments presented mild to intense sedation. In the control group,

Table 1. Times until first vomiting episode and number of dogs that vomited after intramuscular administration of $0.5 \mathrm{mg} / \mathrm{kg}$ morphine (Phases 1 and 2 of the study). Fifteen min before morphine, dogs in the Control, $\mathrm{ACP}_{\mathrm{LD}}, \mathrm{ACP}_{\mathrm{MD}}$ and $\mathrm{ACP}_{\mathrm{HD}}$ groups were administered (IM) physiological saline or acepromazine at doses of 0.025, 0.05 and $0.1 \mathrm{mg} / \mathrm{kg}$, respectively.

\begin{tabular}{ccc}
\hline & $\begin{array}{c}\text { Time until } \\
\text { vomiting (min) }\end{array}$ & $\begin{array}{c}\text { Number of dogs } \\
\text { that vomited }(\%)\end{array}$ \\
\hline Phase 1 & & \\
\hline Control & $3 \pm 1$ & $8 / 8(100 \%)$ \\
$\mathrm{ACP}_{\mathrm{LD}}$ & $3 \pm 1$ & $8 / 8(100 \%)$ \\
$\mathrm{ACP}_{\mathrm{MD}}$ & $3 \pm 0$ & $6 / 8(75 \%)$ \\
$\mathrm{ACP}_{\mathrm{HD}}$ & $4 \pm 1$ & $6 / 8(75 \%)$ \\
\hline Phase 2 & & \\
\hline $\mathrm{Control}$ & $3 \pm 2$ & $19 / 24(79 \%)$ \\
$\mathrm{ACP}_{\mathrm{LD}}$ & $4 \pm 1$ & $6 / 9(67 \%)$ \\
$\mathrm{ACP}_{\mathrm{MD}}$ & $3 \pm 1$ & $9 / 12(75 \%)$ \\
$\mathrm{ACP}_{\mathrm{HD}}$ & $3 \pm 1$ & $5 / 5(100 \%)$ \\
\hline Phases $1+2$ & & \\
\hline $\mathrm{Control}_{\mathrm{ACP}}$ & $3 \pm 2$ & $27 / 32(84 \%)$ \\
$\mathrm{ACP}_{\mathrm{MD}}$ & $3 \pm 1$ & $14 / 17(82 \%)$ \\
$\mathrm{ACP}_{\mathrm{HD}}$ & $3 \pm 1$ & $15 / 20(75 \%)$ \\
\hline
\end{tabular}


Table 2. Mean \pm SD values for pulse rate (PR), systolic (SAP), mean (MAP) and diastolic (DAP) pressure in 8 dogs used in Phase 1. All dogs received $0.5 \mathrm{mg} / \mathrm{kg}$ morphine intramuscularly. Fifteen min before morphine, dogs in the Control, $\mathrm{ACP}_{\mathrm{LD}}, \mathrm{ACP}_{\mathrm{MD}}$ and $\mathrm{ACP}$ groups were administered (IM) physiological saline or acepromazine at doses of $0.025,0.05$ and $0.1 \mathrm{mg} / \mathrm{kg}$, respectively. Timepoint 15 was registered 15 minutes after saline or acepromazine and before morphine. Timepoints 30, 45 and 60 are after morphine administration.

\begin{tabular}{|c|c|c|c|c|c|c|}
\hline & & Baseline & 15 & 30 & 45 & 60 \\
\hline \multirow{4}{*}{$\begin{array}{c}\mathrm{PR} \\
\text { (beats/min) }\end{array}$} & Control & $123 \pm 16^{\mathrm{a}}$ & $103 \pm 14^{\mathrm{a}^{*}}$ & $103 \pm 24^{a}$ & $99 \pm 21^{a^{*}}$ & $98 \pm 28^{a^{*}}$ \\
\hline & $\mathrm{ACP}_{\mathrm{LD}}$ & $116 \pm 19^{a}$ & $112 \pm 20^{\mathrm{a}}$ & $95 \pm 21^{\mathrm{a}}$ & $93 \pm 42^{\mathrm{a}}$ & $98 \pm 52^{\mathrm{a}}$ \\
\hline & $\mathrm{ACP}_{\mathrm{MD}}$ & $121 \pm 18^{a}$ & $113 \pm 18^{a}$ & $96 \pm 18^{a}$ & $102 \pm 36^{\mathrm{a}}$ & $106 \pm 46^{\mathrm{a}}$ \\
\hline & $\mathrm{ACP}_{\mathrm{HD}}$ & $123 \pm 18^{a}$ & $115 \pm 19^{\mathrm{a}}$ & $96 \pm 28^{a^{*}}$ & $90 \pm 23^{a^{*}}$ & $88 \pm 29^{a^{*}}$ \\
\hline \multirow{4}{*}{$\begin{array}{c}\text { SAP } \\
(\mathrm{mmHg})\end{array}$} & Control & $162 \pm 24^{\mathrm{ab}}$ & $146 \pm 15^{\mathrm{a}}$ & $148 \pm 18^{\mathrm{a}}$ & $151 \pm 19^{a}$ & $150 \pm 24^{\mathrm{a}}$ \\
\hline & $\mathrm{ACP}_{\mathrm{LD}}$ & $165 \pm 11^{\mathrm{a}}$ & $132 \pm 18^{a b^{*}}$ & $122 \pm 17^{b^{*}}$ & $116 \pm 16^{b^{*}}$ & $120 \pm 16^{b^{*}}$ \\
\hline & $\mathrm{ACP}_{\mathrm{MD}}$ & $144 \pm 13^{\mathrm{b}}$ & $123 \pm 26^{b^{*}}$ & $123 \pm 13^{b^{*}}$ & $120 \pm 15^{\mathrm{b}^{*}}$ & $119 \pm 14^{b^{*}}$ \\
\hline & $\mathrm{ACP}_{\mathrm{HD}}$ & $164 \pm 25^{\mathrm{a}}$ & $134 \pm 10^{\mathrm{ab} *}$ & $122 \pm 20^{\mathrm{b} *}$ & $112 \pm 12^{b^{*}}$ & $111 \pm 13^{b^{*}}$ \\
\hline \multirow{4}{*}{$\begin{array}{c}\text { MAP } \\
(\mathrm{mmHg})\end{array}$} & Control & $117 \pm 16^{\mathrm{a}}$ & $102 \pm 7^{7^{*}}$ & $101 \pm 14^{\mathrm{a}^{*}}$ & $103 \pm 15^{a^{*}}$ & $106 \pm 16^{\mathrm{a}}$ \\
\hline & $\mathrm{ACP}_{\mathrm{LD}}$ & $118 \pm 7^{\mathrm{a}}$ & $90 \pm 11^{\mathrm{ab}^{*}}$ & $86 \pm 12^{b^{*}}$ & $82 \pm 13^{b^{*}}$ & $83 \pm 11^{b^{*}}$ \\
\hline & $\mathrm{ACP}_{\mathrm{MD}}$ & $104 \pm 13^{b}$ & $86 \pm 12^{b^{*}}$ & $85 \pm 6^{\mathrm{b}^{*}}$ & $84 \pm 11^{b^{*}}$ & $85 \pm 15^{b^{*}}$ \\
\hline & $\mathrm{ACP}_{\mathrm{HD}}$ & $110 \pm 15^{\mathrm{ab}}$ & $92 \pm 8^{\mathrm{ab} *}$ & $86 \pm 15^{b^{*}}$ & $80 \pm 11^{\mathrm{b}^{*}}$ & $77 \pm 9^{b^{*}}$ \\
\hline \multirow{4}{*}{$\begin{array}{c}\text { DAP } \\
(\mathrm{mmHg})\end{array}$} & Control & $89 \pm 12^{\mathrm{ab}}$ & $79 \pm 7^{\mathrm{a}^{*}}$ & $78 \pm 15^{a^{*}}$ & $77 \pm 12^{\mathrm{a}^{*}}$ & $81 \pm 12^{\mathrm{a}}$ \\
\hline & $\mathrm{ACP}_{\mathrm{LD}}$ & $95 \pm 9^{a}$ & $69 \pm 10^{\mathrm{ab}^{*}}$ & $67 \pm 12^{\mathrm{ab}^{*}}$ & $63 \pm 12^{b^{*}}$ & $65 \pm 12^{b^{*}}$ \\
\hline & $\mathrm{ACP}_{\mathrm{MD}}$ & $83 \pm 13^{b}$ & $66 \pm 9^{b^{*}}$ & $65 \pm 6^{\mathrm{b}^{*}}$ & $64 \pm 10^{b^{*}}$ & $67 \pm 14^{b^{*}}$ \\
\hline & $\mathrm{ACP}_{\mathrm{HD}}$ & $91 \pm 14^{\mathrm{ab}}$ & $75 \pm 10^{\mathrm{ab}^{*}}$ & $66 \pm 11^{\mathrm{b}^{*}}$ & $62 \pm 8^{b^{*}}$ & $60 \pm 8^{\mathrm{b}^{*}}$ \\
\hline
\end{tabular}

Within a column, values with one superscript in common do not differ significantly $(P<0.05)$. "Within a row, represents significant difference from baseline $(P<0.05)$.

NDS and SNS scores were significantly greater than baseline at 30, 45 and 60 min. In the $\mathrm{ACP}_{\mathrm{LD}}, \mathrm{ACP}_{\mathrm{MD}}$ and $\mathrm{ACP}_{\mathrm{HD}}$ groups, NDS and SNS scores were significantly increased above baseline from 15 to $60 \mathrm{~min}$ (Table 3). For comparisons among groups in NDS scores, a significant difference was observed between the control and $\mathrm{ACP}_{\mathrm{MD}}$ groups (at 15 and $30 \mathrm{~min}$ ). For SNS scores, significant differences were detected between the $\mathrm{ACP}_{\mathrm{MD}}$ and $\mathrm{ACP}_{\mathrm{HD}}$ groups compared with the control group at selected time points (Table 3 ). The number of dogs presenting intense sedation as judged by the NDS (NDS score = 3) were: $1 / 8,3 / 8,3 / 8$ and $4 / 8$ dogs in the control, $\mathrm{ACP}_{\mathrm{LD}}, \mathrm{ACP}_{\mathrm{MD}}$ and $\mathrm{ACP}_{\mathrm{HD}}$ groups, respectively.

\section{Phase 2}

A total of 50 dogs were enrolled in Phase 2. Demographic data for these dogs are presented in Table 4. There was no significant difference between groups for weight and age of dogs. There was no significant difference between groups in the frequency of vomiting and time elapsed until first vomiting episode.

\section{DISCUSSION}

The hypothesis of the study was rejected. The acepromazine dose did not influence the frequency of morphine-induced vomiting, the degree of sedation or cardiovascular variables after administration of either treatment.

The frequency of vomiting was high $(\geq 75 \%)$ in dogs of the present study regardless of the treatment administered. There was no significant difference in the frequency of vomiting in acepromazine-treated groups $\left(\mathrm{ACP}_{\mathrm{LD}}, \mathrm{ACP}_{\mathrm{MD}}\right.$ and $\left.\mathrm{ACP}_{\mathrm{HD}}\right)$ as compared to the control group. This finding was unexpected. In a previous study in dogs, the overall frequency of opioid-induced vomiting was reduced from $55 \%$ to $18 \%$ when acepromazine $(0.05 \mathrm{mg} / \mathrm{kg}, \mathrm{IM})$ was administered $15 \mathrm{~min}$ before morphine, oxymorphone or hydromorphone [14]. In the same study, the frequency of vomiting was $25 \%$ when acepromazine was administered 15 min before morphine, compared to $75 \%$ when no acepromazine was administered before the opioid [14]. The incidence of morphine-induced vomiting when no acepromazine was administered before morphine was similar in the 
Table 3. Median (interquartile range) sedation scores for the numeric descriptive scale (NDS) and simple numerical scale (SNS) in $8 \mathrm{dogs}$ used in Phase 1 . All dogs received $0.5 \mathrm{mg} / \mathrm{kg}$ morphine intramuscularly. Fifteen min before morphine, dogs in the Control, $\mathrm{ACP}_{\mathrm{LD}}, \mathrm{ACP}_{\mathrm{MD}}$ and $\mathrm{ACP}_{\mathrm{HD}}$ groups were administered (IM) physiological saline or acepromazine at doses of $0.025,0.05 \mathrm{and} 0.1 \mathrm{mg} /$ $\mathrm{kg}$, respectively. Timepoint 15 was registered 15 min after saline or acepromazine and before morphine. Timepoints 30,45 and 60 are after morphine administration.

\begin{tabular}{|c|c|c|c|c|c|c|}
\hline & & Baseline & 15 & 30 & 45 & 60 \\
\hline \multirow{4}{*}{ NDS } & Control & $0.0(0.0-0.0)^{\mathrm{a}}$ & $0.0(0.0-0.8)^{\mathrm{a}}$ & $1.0(0.3-2.0)^{* a}$ & $1.5(1.0-2.0)^{* \mathrm{a}}$ & $2.0(1.0-2.0)^{* \mathrm{aa}}$ \\
\hline & $\mathrm{ACP}_{\mathrm{LD}}$ & $0.0(0.0-0.0)^{\mathrm{a}}$ & $1.0(0.2-2.0)^{* \mathrm{ab}}$ & $1.0(1.0-2.7)^{* \mathrm{ab}}$ & $2.0(1.0-2.7)^{* a}$ & $2.0(1.0-3.0)^{* a}$ \\
\hline & $\mathrm{ACP}_{\mathrm{MD}}$ & $0.0(0.0-0.0)^{\mathrm{a}}$ & $2.0(1.2-2.0)^{* \mathrm{~b}}$ & $2.0(2.0-2.7)^{* b}$ & $2.0(2.0-3.0)^{* a}$ & $2.0(2.0-3.0)^{* a}$ \\
\hline & $\mathrm{ACP}_{\mathrm{HD}}$ & $0.0(0.0-0.0)^{\mathrm{a}}$ & $1.0(1.0-2.0)^{* \mathrm{ab}}$ & $1.5(1.0-3.0)^{* a b}$ & $2.5(1.0-3.0)^{* a}$ & $2.5(1.2-3.0)^{* a}$ \\
\hline \multirow{4}{*}{ SNS } & Control & $0.0(0.0-0.0)^{\mathrm{a}}$ & $0.0(0.0-1.5)^{\mathrm{a}}$ & $2.0(0.5-3.7)^{* a}$ & $3.0(1.2-5.2)^{* a}$ & $3.5(2.2-5.5)^{\mathrm{*a}}$ \\
\hline & $\mathrm{ACP}_{\mathrm{LD}}$ & $0.0(0.0-0.0)^{\mathrm{a}}$ & $2.0(0.2-4.0)^{* a b}$ & $4.0(3.2-6.7)^{* \mathrm{ab}}$ & $6.5(4.0-8.0)^{* a b}$ & $6.5(4.0-8.0)^{* a b}$ \\
\hline & $\mathrm{ACP}_{\mathrm{MD}}$ & $0.0(0.0-0.0)^{\mathrm{a}}$ & $2.5(1.2-4.0)^{* \mathrm{ab}}$ & $5.0(4.0-6.0)^{* b}$ & $6.0(5.2-6.7)^{* a b}$ & $6.0(6.0-7.5)^{* a b}$ \\
\hline & $\mathrm{ACP}_{\mathrm{HD}}$ & $0.0(0.0-0.0)^{\mathrm{a}}$ & $2.5(2.0-3.7)^{* b}$ & $4.5(4.0-7.5)^{* b}$ & $6.0(4.0-8.5)^{* b}$ & $7.0(5.2-8.5)^{* b}$ \\
\hline
\end{tabular}

Within a column, values with one superscript in common do not differ significantly $(P<0.05)$. "Within a row, represents significant difference from baseline $(P<0.05)$.

Table 4. Demographic data for $50 \mathrm{dogs}$ included in Phase 2. Values for weight and age are presented as mean \pm SD (range). All dogs received $0.5 \mathrm{mg} / \mathrm{kg}$ morphine intramuscularly. Fifteen min before morphine, dogs in the Control, $\mathrm{ACP}_{\mathrm{LD}}, \mathrm{ACP}_{\mathrm{MD}}$ and $\mathrm{ACP}_{\mathrm{HD}} \mathrm{groups}_{\mathrm{Were}}$ administered (IM) physiological saline or acepromazine at doses of $0.025,0.05$ and $0.1 \mathrm{mg} / \mathrm{kg}$, respectively.

\begin{tabular}{|c|c|c|c|c|}
\hline & Breed & Sex & Body weight (kg) & Age (months) \\
\hline Control $(n=24)$ & $\begin{array}{c}\text { Crossbreed }(\mathrm{n}=13) \\
\text { Poodle }(\mathrm{n}=3) \\
\text { Beagle }(\mathrm{n}=2) \\
\text { Bull Terrier }(\mathrm{n}=1) \\
\text { Chow Chow }(\mathrm{n}=1) \\
\text { Cocker Spaniel }(\mathrm{n}=1) \\
\text { German Spitz }(\mathrm{n}=1) \\
\text { Dachshund }(\mathrm{n}=1) \\
\text { Yorkshire Terrier }(\mathrm{n}=1)\end{array}$ & $\begin{array}{l}M(n=3) \\
F(n=21)\end{array}$ & $\begin{array}{l}11.2 \pm 5.5 \\
(4.5-23.7)\end{array}$ & $\begin{array}{l}41 \pm 42 \\
(5-144)\end{array}$ \\
\hline $\mathrm{ACP}_{\mathrm{LD}}(\mathrm{n}=9)$ & $\begin{array}{c}\text { Crossbreed }(n=6) \\
\text { Golden Retriever }(n=1) \\
\text { Labrador Retriever }(n=1) \\
\text { Poodle }(n=1)\end{array}$ & $\begin{array}{c}M(n=4) \\
F(n=5)\end{array}$ & $\begin{array}{c}17.8 \pm 13.1 \\
(2.6-44.7)\end{array}$ & $\begin{array}{l}47 \pm 32 \\
(7-108)\end{array}$ \\
\hline $\mathrm{ACP}_{\mathrm{MD}}(\mathrm{n}=12)$ & $\begin{array}{c}\text { Crossbreed }(n=4) \\
\text { Poodle }(n=3) \\
\text { Pinscher }(n=2) \\
\text { Labrador Retriever }(n=1) \\
\text { German Shepherd Dog }(n=1) \\
\text { German Spitz }(n=1)\end{array}$ & $\begin{array}{c}M(n=5) \\
F(n=7)\end{array}$ & $\begin{array}{c}12.1 \pm 10.4 \\
(2.5-33.5)\end{array}$ & $\begin{array}{l}45 \pm 36 \\
(8-120)\end{array}$ \\
\hline $\mathrm{ACP}_{\mathrm{HD}}(\mathrm{n}=5)$ & $\begin{array}{c}\text { Maltese }(\mathrm{n}=1) \\
\text { Belgian Shepherd }(\mathrm{n}=1) \\
\text { Poodle }(\mathrm{n}=1) \\
\text { Crossbreed }(\mathrm{n}=1) \\
\text { Dachshund }(\mathrm{n}=1)\end{array}$ & $\begin{array}{c}M(n=3) \\
F(n=2)\end{array}$ & $\begin{array}{c}12.1 \pm 11.1 \\
(6.5-31.1)\end{array}$ & $\begin{array}{l}65 \pm 35 \\
(12-96)\end{array}$ \\
\hline
\end{tabular}


present study (control group $=84 \%$ ) and the other study (75\%) [14]. However, when acepromazine was administered 15 min before morphine, a much higher incidence of vomiting was observed in our study $\left(82 \%, 75 \%\right.$ and $85 \%$, in the $\mathrm{ACP}_{\mathrm{LD}}, \mathrm{ACP}_{\mathrm{MD}}$ and $\mathrm{ACP}_{\mathrm{HD}}$ groups) compared to the $25 \%$ value observed in the previous study [14].

Two reasons may have contributed for the discrepancies between this and the previous study: a) fasting period; and b) definition of vomiting. Food but not water was withheld for $12 \mathrm{~h}$ in the present study. No information about fasting was found in the study by Valverde et al. [14] in 2004. A longer fasting period and/or water deprivation might contribute to decrease the incidence of vomiting. In our study, abdominal contractions followed by attempts to expel gastric contents were considered as vomiting episodes even if nothing had been expelled. In the other study, retching and vomiting were evaluated separately [14]. It is possible that some vomiting episodes in our study might be considered as retching episodes in the previous study [14].

The sedative effect induced by acepromazine-opioid combinations has been extensively studied in dogs $[2,4,7,9,10,13]$. To the authors' knowledge, this is the first study to report the influence of dose of the phenothiazine on the sedating action of the combination. In the present study, $\mathrm{ACP}_{\mathrm{LD}}, \mathrm{ACP}_{\mathrm{MD}}$ and $\mathrm{ACP}_{\mathrm{HD}}$ improved the quality of sedation compared to the control treatment, although a significant difference from controls was only detected for the $\mathrm{ACP}_{\mathrm{MD}}$ and $\mathrm{ACP}_{\mathrm{HD}}$ treatments. No difference in sedation scores was observed among the $\mathrm{ACP}_{\mathrm{LD}}, \mathrm{ACP}_{\mathrm{MD}}$ and $\mathrm{ACP}_{\mathrm{HD}}$ treatments. These findings suggest that, when combined to morphine, there is no improvement in sedation when the acepromazine dose is increased above 0.025 $\mathrm{mg} / \mathrm{kg}$ in dogs.

Cardiovascular adverse effects observed in this study were decreased PR (control and $\mathrm{ACP}_{\mathrm{HD}}$ treatments) and decreased blood pressure (most notably in the $\mathrm{ACP}_{\mathrm{LD}}, \mathrm{ACP}_{\mathrm{MD}}$ and $\mathrm{ACP}_{\mathrm{HD}}$ treatments). The decrease in PR is likely the result of opioid-induced increase in parasympathetic tone [5]. The reduction in blood pressure is most likely associated to acepromazine administration. It has been proposed that the blockade of alpha-1 adrenergic receptors at vascular beds results in vasodilation and consequently, decrease in arterial blood pressure [6,11]. In the present study, no significant differences in SAP, MAP or DAP were detected among the $\mathrm{ACP}_{\mathrm{LD}}, \mathrm{ACP}_{\mathrm{MD}}$ and $\mathrm{ACP}$ treatments. These findings indicate that the effect of acepromazine on blood pressure of conscious-sedated dogs is not influenced by the dose of the phenothiazine. Despite a significant decrease, mean values of PR, SAP, MAP and DAP remained within the physiological range for conscious dogs [3].

One limitation of this study was the inclusion of data records from $18 \mathrm{dogs}$ of another research study in Phase 2. The inclusion of this data prevented randomization of the treatment, as all $18 \mathrm{dogs}$ were included in the control group. As a result, more dogs were assigned to the control group than other groups in Phase 2. Although the authors consider this a limitation of the study, we believe that the inclusion of data from these 18 dogs had little influence on the overall frequency of vomiting in the control group. The incidence of vomiting was high in all groups in Phases 1 and 2 of the study.

\section{CONCLUSION}

In summary, none of the acepromazine doses was effective in preventing morphine-induced vomiting in dogs. Sedation is greater after acepromazine-morphine combinations than after morphine alone and is not influenced by the acepromazine dose. Cardiovascular effects induced by drugs administered in this study were well tolerated and of little clinical relevance to healthy conscious dogs.

\section{MANUFACTURERS}

${ }^{1}$ Laboratório Vetnil. Louveira, SP, Brazil.

${ }^{2}$ Labaratório Cristália. São Paulo, SP, Brazil.

${ }^{3}$ Ramsey Medical Inc. and Cardio Command Inc. Tampa, FL, USA.

Ethical approval. The study was approved by the University of Vila Velha Institutional Animal Care Committee (protocol 271/2013).

Declaration of interest. The authors report no conflicts of interest. The authors alone are responsible for the content and writing of paper. 


\section{REFERENCES}

1 Bitti F.S., Campagnol D., Rangel J.P., Nunes Junior J.S., Loureiro B. \& Monteiro E.R. 2017. Effects of three methadone doses combined with acepromazine on sedation and some cardiopulmonary variables in dogs. Veterinary Anaesthesia and Analgesia. 44(2): 237-245.

2 Gomes V.H., Monteiro E.R., Dias R.S., Oliveira R.L.S., Silva M.F.A. \& Coelho K. 2011. Comparison of the sedative effects of morphine, meperidine or fentanyl, in combination with acepromazine, in dogs. Ciência Rural. 41(8): 1411-1416.

3 Haskins S., Pascoe P.J., Ilkiw J.E., Fudge J., Hopper K. \& Aldrich J. 2005. Reference cardiopulmonary values in normal dogs. Comparative Medicine. 55(2): 156-161.

4 Hofmeister E.H., Chandler M.J. \& Read M.R. 2010. Effects of acepromazine, hydromorphone, or an acepromazinehydromorphone combination on the degree of sedation in clinically normal dogs. Journal of the American Veterinary Medical Association. 237(10): 1155-1159.

5 KuKanich B. \& Wiese A. 2015. Opioids. In: Grimm K.A., Lamont L.A., Tranquilli W.J., Greene S.A. \& Robertson S.A. (Eds). Lumb \& Jones Veterinary Anesthesia and Analgesia. 5th edn. Ames: Wiley Blackwell, pp.207-226.

6 Ludders J.W., Reitan M.D., Martucci M.A., Fung D.L. \& Steffey E.P. 1983. Blood pressure response to phenylephrine infusion in halothane-anesthetized dogs given acetylpromazine maleate. American Journal of Veterinary Research. 44: 996-999.

7 Monteiro E.R., Figueroa C.D., Choma J.C., Campagnol D. \& Bettini C.M. 2008. Effects of methadone, alone or in combination with acepromazine or xylazine on sedation and physiologic values in dogs. Veterinary Anaesthesia and Analgesia. 35(6): 519-527.

8 Monteiro E.R., Lobo R.B., Nunes Junior J.S., Rangel J.P. \& Bitti F.S. 2016. Tramadol does not enhance sedation induced by acepromazine in dogs. Canadian Journal of Veterinary Research. 80(4): 323-328.

9 Monteiro E.R., Nunes Junior J.S. \& Bressan T.F. 2014. Randomized clinical trial of the effects of combination of acepromazine with morphine and midazolam on sedation, cardiovascular variables and the propofol dose requirements for induction of anesthesia in dogs. The Veterinary Journal. 200(1): 157-161.

10 Monteiro E.R., Rodrigues Junior A., Assis H.M., Campagnol D. \& Quitzan J.G. 2009. Comparative study on the sedative effects of morphine, methadone, butorphanol or tramadol, in combination with acepromazine in dogs. Veterinary Anaesthesia and Analgesia. 36(1): 25-33.

11 Monteiro E.R., Teixeira Neto F.J., Castro V.B. \& Campagnol D. 2007. Effects of acepromazine on the cardiovascular actions of dopamine in anesthetized dogs. Veterinary Anaesthesia and Analgesia. 34(5): 312-321.

12 Rankin D.C. 2015. Sedatives and Tranquilizers. In: Grimm K.A., Lamont L.A., Tranquilli W.J., Greene S.A. \& Robertson S.A. (Eds). Lumb \& Jones Veterinary Anesthesia and Analgesia. 5th edn. Ames: Wiley Blackwell, pp.196-206.

13 Stepien R.L., Bonagura J.D. \& Bednarski R.M. 1995. Cardiorespiratory effects of acepromazine maleate and buprenorphine hydrochloride in clinically normal dogs. American Journal Veterinary Research. 56(1): 78-84.

14 Valverde A., Cantwell S., Hernández J. \& Brotherson C. 2004. Effects of acepromazine on the incidence of vomiting associated with opioid administration in dogs. Veterinary Anaesthesia and Analgesia. 31(1): 40-45.

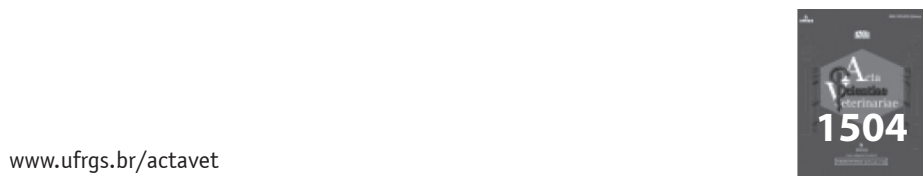

